\title{
The BBC Television Audience Research Reports, 1957-1979: recorded opinions and invisible expectations
}

Article

Accepted Version

Smart, B. (2014) The BBC Television Audience Research Reports, 1957-1979: recorded opinions and invisible expectations. Historical Journal of Film, Radio and Television, 34 (3). pp. 452-462. ISSN 0143-9685 doi:

https://doi.org/10.1080/01439685.2014.937187 Available at https://centaur.reading.ac.uk/71886/

It is advisable to refer to the publisher's version if you intend to cite from the work. See Guidance on citing.

Published version at: http://dx.doi.org/10.1080/01439685.2014.937187

To link to this article DOI: http://dx.doi.org/10.1080/01439685.2014.937187

Publisher: Taylor \& Francis

All outputs in CentAUR are protected by Intellectual Property Rights law, including copyright law. Copyright and IPR is retained by the creators or other copyright holders. Terms and conditions for use of this material are defined in the End User Agreement.

www.reading.ac.uk/centaur 
Central Archive at the University of Reading

Reading's research outputs online 


\section{THE BBC TELEVISION AUDIENCE RESEARCH REPORTS, 1957-79: RECORDED OPINIONS AND INVISIBLE EXPECTATIONS.}

\section{Dr Billy Smart}

\section{Introduction}

Between the 1950s and the 1980s, the BBC's internal Audience Research Unit compiled up to 700 Audience Research Reports for television per annum, attempting to cover the complete spectrum of BBC TV programming. This article considers the form, value and possible future application of this material, reflections inspired by my own use of the collection when researching $\mathrm{BBC}$ adaptations of theatrical classics in order to examine the use of space in these dramas in the 1970s; the locations that programmes were made in, the fictional settings represented onscreen, and viewers' spatial understanding of these programmes. In this piece I shall describe the form that the Audience Research Reports took and explain their use to historians. I shall then describe two methodologies that I have used in my work. Through the study of a large number of reports made for similar programmes spread across a number of years, researchers can form detailed, nuanced, conclusions about the development of audience responses towards the programmes in question. This article demonstrates this through charting audience responses in the 1970s towards adaptations of theatrical plays made on Outside Broadcast, which evolve as the form of programme becomes less novel and more familiar. I then suggest how, by detailed reading of a large number of reports, it is possible to establish the framework of expectations through which viewers understood specific types of programmes, making it possible to determine reactions not articulated by audiences in the reports. 
The reports (kept at the BBC Written Archives in Caversham) took a standardized form, divided into several sections, providing; transmission details, an estimate of the audience size in terms of percentage of the UK population, an attempt to gauge audience reception (the Reaction Index) through a mark out of 100 compiled by asking viewers to rate the programme seen on a five point scale, and several paragraphs of commentary. ${ }^{1}$ This information was collected either through face-toface interview or questionnaires. In reports for drama programmes, the commentary is often structured into separate paragraphs presenting a case for and against the individual programme, followed by sections detailing audience evaluation of the performances contained within, and the perceived style of, the production.

\section{Example of a typical Audience Research Report: Play of the Month: Pygmalion}

(BBC1, 16 December 1973)

\section{AN AUDIENCE RESEARCH REPORT}

(Week 51) VR/73/714

Play of the Month

Shaw's PYGMALION

Producer: Christopher Morahan

Sunday, $16^{\text {th }}$ December 1973. 8.15-10.15 pm. BBC-1

1. Size of audience (based on results of the Survey of Listening and Viewing). It is estimated that the audience for this broadcast was $18 \%$ 
of the United Kingdom population. Programmes on BBC-2 and ITV at the time were seen by $6.8 \%$ and $21 \%$ (averages).

2. Reaction of audience (based on 295 questionnaires completed by $18 \%$ of the Viewing Panel). The reactions of this sample of the audience were distributed as follows:-

$$
\text { A }+21 \% \text { A } 46 \% \text { B } 26 \% \text { C 5\% C- } 0 \%
$$

Giving a REACTION INDEX of 71. In weeks 29, 38, 43 and 47, the figures were $63,53,59$ and 51 respectively.

3. Undoubtedly, the majority greatly enjoyed this version of Eliza Doolittle's transformation from Cockney flower-seller to high society 'lady' in Shaw's Pygmalion. It was 'Shaw at his best', and 'a real evergreen', according to some, though a less enthusiastic minority, regarding it as 'pretty thin stuff today', found it boring in parts, and decidedly 'too old-hat'. Some were also disappointed, it seems, at an apparent departure from the original: they could see no reason, they said, for an alteration to the script, which, in their view, was 'no improvement'. But, despite the many versions claimed to have been seen by some (from school plays to the musical My Fair Lady), this Pygmalion greatly appealed to most of the sample.

4. Generally speaking, the entire cast was considered good, although there were some criticisms of over-acting (especially by James Villiers), and 'unconvincing' accents (notably Lynn Redgrave's). However, as one viewer remarked, 'this kind of Cockney accent doesn't really 'belong” today so is bound to feel artificial', and, as has 
been said, the cast as a whole was thought to have given a splendid performance.

5. Apart from one or two critics, seemingly disturbed at times by 'wobbly' props (staircase and walls, in particular), there was widespread agreement that the overall production contributed greatly to viewers' enjoyment - costumes, make-up, sets (especially in the bathtub scene), all receiving special mention as imparting a good period flavor.

6. $85 \%$ watched the whole play; $7 \%$ came in in the middle; $5 \%$ switched off before the end, and 3\% just tried a bit.

$\mathrm{JMS} / \mathrm{MH}$

Audience Research Department $15^{\text {th }}$ January 1974

This typical report (the $714^{\text {th }}$ collated in 1973) provides the researcher with more than just statistical information, but suggests something of how audiences interpreted such a play, and the frame of reference through which they viewed it. The five-point scale of the Reaction Index (with A+ recording great approval, A appreciation, B a normal reaction, $\mathrm{C}$ for antipathy and $\mathrm{C}$ - representing active dislike) provides us with a fairly sophisticated barometer for understanding audience reaction. In this instance we can see that Pygmalion was a production to which few viewers disliked, and to which none took great exception, and from which almost half of the audience derived real, but not exceptional, engagement and approval.

The further reactions articulated in the rest of the report demonstrate how the audience's response to this specific programme was conditioned by the familiarity of the material, a 'real evergreen' play which viewers could detect alterations made to. The report suggests that advance knowledge of Shaw's play predisposed this 
particular audience to forgive the flaws and inconsistencies that they observed, the inconsistent accents and wobbling sets failing to stop the enjoyment derived from performances and attractive period production values.

The Pygmalion report illustrates the unique value of the BBC's Audience Research for historians: helping us to understand what people thought about a range of television at the time that it was broadcast, rather than retrospectively. Other sources, such letters to newspapers and magazines, only record exceptional responses of either praise or condemnation. But the great value of the Audience Research Reports lies in their record of everyday responses, which would otherwise have been quickly forgotten and lost forever, to the whole range of BBC programming, unlike the work of professional television critics.

\section{'Spaces of Television' Case Study: Classic BBC Drama made on Outside}

\section{Broadcast.}

Conducting such research, through looking across a range of reports into similar programming spanning a long period of time, has supported work on the AHRC 'Spaces of Television: Production, Site \& Style' historical project examining the use of space in British television drama from the ' $50 \mathrm{~s}$ to the ' $90 \mathrm{~s}$; the spaces that programmes were made in, the spaces represented onscreen, and viewers' spatial understanding of these programmes.

One study into the changing form of television drama in Britain has been through looking at television dramas made on Outside Broadcast (i.e. recorded away from the studio by electronic cameras onto videotape - the same equipment used to relay sports and public events - not on film) a development that started with the 
adoption of colour television in the late 1960s. This form of drama becomes more prevalent with the introduction of new camera technology designed especially for location work in the '70s, and requiring a smaller unit, of two cameras and a soundman, than previously needed.

Outside Broadcast technology had major potential benefits for broadcasters, particularly the fiscal advantage of being cheaper than film. The amount of footage that could be recorded on OB made it much more productive than film, able to produce over ten minutes of drama in a day. ${ }^{2}$ Videotape was much more adaptable to changing states of natural light than film, and recording could continue in conditions such as drizzle, that would stop production on film. Sound-recording was more immediate and less complex than on film, with actors having radio mikes, and the signal being fed directly into the tape, obviating the need to redub and post-synch. This sense of immediacy was also accentuated by the crisper image and greater depth of field that videotape could show, so that, for example, the detail of individual bracken and ferns in the open could be picked up by the camera, a potentially promising development for the drama of spectacle and decorative detail. The mobility of the OB units also greatly opened up the range of locations that could be used, shooting in wildernesses miles from civilisation becoming practicable.

These advantages were balanced by equivalent disadvantages. The more immediate sound recording onto tape was also less defined than in post-dubbed film or studio sound, running the risk of dialogue becoming muffled by simultaneous local sound such as wind, footsteps, or the echo of location interiors. The greater depth of field that could be achieved on videotape could also be distracting for the viewer, showing long takes of locations in complete and undiscriminating detail, rather than the more nuanced focusing that was an established part of film technique. The 
personnel of Outside Broadcast units were specialised technicians, specifically trained for working on $\mathrm{OB}$, and therefore with little experience of working with drama, unlike established location film units, who offered a well-established set-up, drawing upon decades of experience in the British film industry. The crews that operated the new OB technology were still inexperienced in working with multiple angles and set-ups, or dramatic framing and grouping, these techniques not having been needed in their experience of recording sports and events, leading to a preponderance of scenes recorded in long-shot, unlike in filmed or studio drama. ${ }^{3}$

\section{Classic plays made on Outside Broadcast by the BBC in the 1970 s.}

Ten BBC TV versions of classic plays were produced on location in the 1970s; $A$ Midsummer Night's Dream (1971), The Duchess of Malfi (1972), The Love-Girl and the Innocent (1973), The Recruiting Officer (1973), Twelfth Night (1974), The Little Minister (1975), Love's Labour's Lost (1975), London Assurance (1976), As You Like It (1978) and Henry VIII (1979). These Outside Broadcast adaptations were recorded on sites considered specifically suitable for their source material, recreating theatrical scenes in existing locations such as countryside, parks, streets and historic buildings.

The willingness of the producer of all ten plays, Cedric Messina, to make adaptations on $\mathrm{OB}$ can in part be attributed to his strong theatrical impresario/showman's instincts; historical locations such as castles and stately homes, set in landscaped gardens and verdant countryside, offered great opportunities for arresting spectacle and decorative detail. Sometimes the availability of a location partially dictated the choice of play, as with the 1975 Love's Labour's Lost, one of Shakespeare's least performed and hardest to follow plays: 
Well, we wanted to do another Shakespeare comedy. And I particularly wanted a play that was set in the open air. In this, all the action takes place in the open air. We recorded it at Glyndebourne. It looks lovely. All the girls are very, very pretty. They look like Botticelli paintings. ${ }^{4}$

For Messina, the beauty of Glyndebourne as location acted as justification for the demanding choice of play; "I hope that when people switch on, they will see all these glorious Renaissance creatures wandering around these beautiful gardens and they'll stay with it". ${ }^{5}$ Historical exteriors were also more likely to garner publicity than studio recording because of the presence of star actors in public locations, and the owners of heritage sites wishing to promote them to an audience of potential visitors.

An assumption surrounding outside broadcast drama was that, by being filmed in real fields, streets and houses, it could be seen as closer to reality, and therefore more authentic, than drama that recreated such locations in the studio. Viewers had continually complained in reports that attempts to represent exterior locations in the studio were distractingly unrealistic. I wanted to find out how audiences responded to theatrical plays that were made in real exteriors under OB conditions. Although not all ten of the programmes survive in $\mathrm{full}^{6}$, we do have an Audience Research Report for every one, providing a real insight into how audiences came to view these programmes differently once the form became more familiar to them.

Audience responses to these adaptations were decidedly mixed. Although many viewers generally responded favourably to the natural attractiveness of the locations for example the Audience Research Report for Love's Labour's Lost reported that "The delightful surroundings of Glyndebourne 'created an air of courtly enchantment' that was 'exquisite' and 'lovely", 7 or that "magnificent Castle Howard had provided 
a beautiful setting" for Twelfth Night ${ }^{8}$ - the OB conditions had also frequently made these productions hard for viewers to follow. This incoherence particularly applied to dialogue, both in exterior scenes, such as the muffled forest scenes of $A$ Midsummer Night's Dream ${ }^{9}$ and interiors: the "reverberant acoustics of Castle Howard made it difficult to hear all the words, particularly Olivia and Sir Toby Belch" (Twelfth Night $){ }^{10}$ the "sound tended to be 'erratic' and the indoor acoustics, with footsteps echoing on carpeted floors, made parts of the dialogue difficult to hear" (The Recruiting Officer). ${ }^{11}$

As OB productions became a more familiar experience for viewers, dissatisfaction with the form became more prevalent and vocal. Viewers complained that they found real- life conditions and lighting distracting, "variable weather conditions spoiled it slightly" (Love's Labour's Lost), ${ }^{12}$ and the selection of locations started to become repetitive. ${ }^{13}$ By the 1974 Twelfth Night viewers started to sense that the decorative settings were becoming counterproductive; "'The settings were magnificent, but they often distracted from and overshadowed the play', the production taking full advantage of the range of locations made available through the free access to Castle Howard, the use of corridors and bathrooms becoming 'claustrophobic". ${ }^{14}$ By the time of Love's Labour's Lost, a section of viewers are prepared to pronounce that they "dislike outdoor productions in general". ${ }^{15}$

These reactions reveal a central paradox inherent to the form of OB productions of classic plays made in this period. The OB technology allowed Messina to pursue his interest in creating an aesthetic of decorative visual pleasure through recording in castles, stately homes, gardens and forests, but also meant that these locations were experienced by the viewer with a degree of murkiness in terms of sound and lighting with looming clouds and echoing floors, undermining the attractive aesthetic through 
the uncomfortable constant presence of realism.

\section{Establishing the audience's framework of expectations}

Although examples taken from Audience Research Reports are often cited in studies, they have generally been used to support analysis of individual programmes. When researching my TV theatrical adaptation, I read every Audience Research Report for such productions collated between 1957 and 1985. This meant that I could support my interpretations of audience research into my case studies with reference to documentation for similar productions, noting the recurring patterns and formulations of praise and censure that frequently appear in viewers' comments. This methodology provided a credible source for establishing the framework of expectations with which viewers approached programmes, and could be equally well applied to many other forms of television made in this period. I took my methodological lead from Tracy Hargreaves' writing about the phenomenally successful 1967 BBC2 adaptation of John Galsworthy's Forsyte Saga novels. ${ }^{16}$

Hargreaves concentrates her research away from contemporaneous television and literary criticism to examining a different range of sources that prioritise the responses of non-professional critics; BBC audience research, newspaper letters and subsidiary discussions of the saga on television programmes such as Late Night LineUp (BBC2, 1966-72) and Talkback (BBC1, 1967-72). These disparate sources reveal much as to how viewers responded to the saga as a television programme, through their patterns of viewing and the values that they found reflected in the series. To form a conclusion on the basis of these various views requires a process of synthesis on the part of Hargreaves, as viewers sometimes presented contradictory reactions simultaneously, regarding period adaptation as a form of drama that existed outside of 
the conventions of contemporary television drama while at the same time, unconsciously, responding to it in ways that were defined by these conventions.

Hargreaves assembles a portfolio of contemporaneous praise for the series, praise which is often articulated in terms of what the programme was not, with the series creating an immersive and addictive experience for the audience, enabling them to travel into a well-dressed and prosperous Edwardian world typified by a formal register of speech and behaviour, a place of respite from present-day concerns. In the words of one viewer:

We are sick to death of living in a world where we are exhorted to be different from what we are by critics and politicians. We are tired of having a guilty conscience if we are luckier than our neighbours and of trying to take the burdens of Vietnam and Biafra on our shoulders. Above all, we are sick of the sight and sound of scruffy teenagers and students and kitchen sink drama! No wonder we are happy to escape for 45 minutes each week into a world of elegance and good manners and to enjoy the superb acting of Margaret Tyzak and Eric Porter. ${ }^{17}$

I often found similar formulations of praise for BBC theatrical adaptations in my research, united by their taking the form of praising a programme for what it was not, often for the absence of swearing, explicit sex, pretentious experimentalism or leftwing politics. For example, a 1969 Play of the Month production of Henry James' The Heiress:

“Other delighted viewers welcomed it as a play with 'a real story', which kept them interested and 'guessing' right to the end. It was a pleasure to have a 'well 
constructed, complete play', they also said, with a 'definite' ending, that, 'unlike so many others' did not 'leave one wondering'. This was a very refreshing change from kitchen sink sex, violence and 'Wednesday rubbish', a few added."18

Although such criticisms are helpful in locating productions within a wider context of more overtly contentious television drama in Britain, in order to be fully understood they must be considered with reference to what it was about these programmes to which viewers responded positively, as well as to what they were seen as uncontaminated by. The qualities that viewers found in these productions are also the same as those that constitute the theatrical style as defined by Richard Dyer, ${ }^{19}$ of particular importance to understanding audience reception of the classic play; a preoccupation with manners, the primacy of articulate verbal communication, and a continuity of class between the characters onscreen and the viewer.

Hargreaves' methodology of analysing reception documents through their contradictions and absences, is an especially pertinent one for the study of the classic theatrical adaptation, and is one that I applied in my study of BBC audience research documents. I propose that the form of the audience research report for the classic Edwardian play is built around a framework of expectation on the part of the viewer that is not consciously articulated. Hargreaves' viewers of The Forsyte Saga watched within a framework of expectation that its period setting meant that it would not contain swearing, incomprehensible experimentation, or hectoring left-wing politics, but that the programme would operate around a different register of values than contemporary plays and series; elegance of language and décor, the opportunity to experience a particularly rich form of character acting; an immersive experience of 
life in a different era; a sense of charm.

\section{The framework of expectations for the classic stage play on BBC Television.}

Across the range of audience reports for classic theatrical adaptations similar frameworks of expectation can be discerned through the frequent recurrence of certain formulations or terms of praise, to the extent where they are almost never omitted; that the plays would present particularly strong, gripping and intriguing narratives; that they would have a sense of visual style in settings, décor and costumes; and that they would provide a particular forum to experience acting of a high quality in exceptionally demanding and rewarding parts - what the Radio Times called "the biggest stars in the biggest roles".

The recurring formulations of approval for these attributes formed orthodoxy of expectation on the part of viewers, meaning that an attentive historian of audience research can detect an unarticulated register of disappointment when productions failed to provide these pleasures. In the audience research that I presented I could point out incidences when the audiences' framework of expectations were not met, and tease out implications from these examples for the mainstream broadcasting of the classic theatrical adaptation as a whole.

For example, between 1975 and 1977, the BBC made three productions of John Galsworthy's plays, The Skin Game, Strife and Loyalties. The glowing reactions to Loyalties show that the production fulfilled the audience's framework of expectations for a well-made play of the early $20^{\text {th }}$ Century with exceptionally high viewing figures of $17.5 \%$, and appreciative Reaction Index of 72 . This strong approval was due to three factors; firstly, the strength of the narrative: 
Loyalties proved to be a popular choice for Play of the Month, many of the sample welcoming 'a good old-fashioned play', 'a real classic'. It was a pleasure to see 'such professionalism in the writing and construction': 'a change from today's plays', and a significant group were apparently happy with a story that had a clearly developing plot-line: 'You can't beat a drama with a beginning, a middle and an end, which current ones tend not to have'; 'exceptionally well made, absorbing from start to finish'. ${ }^{20}$

Secondly, this clarity of storytelling supported a theme that was itself obvious and of interest to viewers:

Also, the problems caused by conflicting notions of correct behaviours proved an interesting and not-so-unusual subject (except for a small number who felt such preoccupations [irrelevant] to present-day society). For others, the contrast between then and now 'added another absorbing dimension'. 'It was interesting to see how people's attitudes had changed towards the gravity of dishonourable conduct'. In addition, the relationships within the play were very well drawn: 'an acutely observed interplay of characters and motivations'; presenting 'sympathetically a very real dilemma'. ${ }^{21}$

In addition to the story and theme, viewers (including those who were unconvinced by the plot or subject) responded with pleasure to the programme's production values:

A strong current of approval ran through the sample for the accuracy of the period atmosphere: 'the production captured the 'twenties atmosphere very 
well', and this appeared to be an important factor in the sample's evident enjoyment. The costumes and sets (particularly in the Club) were felt to be 'just right $^{22}$

However, when Galsworthy's Strife, a play about a striking tin miners with few female characters, offering little scope for attractive period costume and décor, was transmitted in the same slot, the tone of the audience research is one of disappointment, which can largely be explained by viewers' unarticulated expectations of what they might expect to see in an Edwardian play being unsatisfied. Enthusiastic and bored viewers alike found that their response to Strife was affected by the play's contemporary relevance to the British miners' strikes of 1972 and 1974. For the positive camp, this meant that although "this was a play for its own time, it still had something to say today", while for those who had not enjoyed the production;

The reminder of present-day industrial strife made the play less appealing, even decidedly depressing, they were tired of 'incessant wrangling' between workers and employers and wanted 'something more cheering in evening plays'. ${ }^{23}$

What unites both viewpoints is an expectation that the production of classic plays such as Strife on BBC1 should evoke the sense of a different time, with this distance from the present creating either a stimulating or a cheering effect. Relevance to contemporary politics was not an expected aspect of the Play of the Month adaptation. Being reminded of contemporary concerns through such programmes had a different effect upon viewers of a studio adaptation than in filmed drama series such as Ken 
Loach's Days of Hope (BBC1, 1976) that, through cinematic conventions of realism and being original contemporary works for television, created a different framework of expectations with which the viewer approached the programme.

Once this framework of expectations has been established, one can detect different allowances made on the part of viewers to the classic play than in other forms of drama. Once viewers felt confident in the strength of a play's narrative they were then prepared to allow for a greater degree of leeway in how that narrative unfolded. The audience reaction to plays like Loyalties or Pygmalion sees these programmes as being old-fashioned and slightly creaky, but viewers report enjoyment of this theatrical exposition, because the strong storyline offered a different register of sustained pleasure to other television drama. Once that expectation of narrative was broken, however, for example in $\mathrm{BBC}$ productions of Chekhov, then the programmes angered audiences.

Similarly, if audiences' expectations of visual pleasure (specifically in terms of setting and costume) were fulfilled, audiences were prepared to overlook deficiencies in their realisation, in the wobbling sets or camerawork of Pygmalion, or in the lighting and sound of 1970 s OB productions. When plays were presented that did not allow the same register of visual pleasure, though, such as the slums and boardroom settings of Strife, Audience Research indicates a disappointment, even if the desire for visual pleasure is not consciously articulated. Having established this framework of expectations, one is then better equipped to fully understand the ramifications of audience reaction to complex productions.

\section{Conclusion: Audience research and decoding audience expectations}

Throughout my research into the classic theatrical adaptation, I made extensive use of 
BBC Audience Research Reports. Through researching the complete range of reports compiled over twenty-five years for one genre of television drama, I was able to document the recurring patterns of praise and censure that frequently appeared in viewers' comments. It is only through detailed study of the complete range of this audience research that one can understand its full implications for reaching a greater understanding of how television drama was experienced by viewers. For example, it is only through observing the frequency with which specific aspects of the programmes are mentioned (attractive sets and costumes or intelligible storylines) that one notices the infrequent occasions where they do not appear, deepening one's understanding of viewer reaction for that particular programme. Viewers approached many television programmes through a framework of expectations that they had learned to acquire through years of watching other television (as well as through their experience of radio, cinema and theatre), expectations that were rarely articulated. The remarkable extensiveness of the BBC Audience Research collated during this period provides a potentially invaluable source for increasing our understanding of the preconceptions with which people viewed television. A comprehensive overview of this material, that documented the recurring expectations of viewers, explained how these expectations were articulated, and tracked how these arguments developed and mutated between the 1950s and the 1980s as a whole, would form a valuable contribution to television studies.

\section{Acknowledgements}


This article is one of the outcomes of the research project "Spaces of Television:

Production, Site and Style", funded by the Arts \& Humanities Research Council from

2010-15.

\section{References}

\footnotetext{
${ }^{1}$ The form of the reports did evolve over time. For example, the Reaction Index is replaced by more complex statistical tables for a while in the early 1970s, there is a brief experiment with expanding the remit of the Audience Research Department through compiling reports into rival ITV programmes in 1976 and 1977, and the professions of individual respondents are given in reports of the 1950s and 1960s.

${ }^{2}$ The average rate of footage produced per day on $\mathrm{OB}$ for BBC drama in 1979 was six minutes, as opposed to two and a half on film (Sutton, Shaun, The Largest Theatre In The World, London: BBC 1982, p. 99). Early Play of the Month OB productions experimented with tighter schedules, James Cellan Jones' 1971 Midsummer Night's Dream being filmed at Scotney Castle over just four days, an exercise that the director retrospectively considered to have been logistical "madness" and artistically unsuccessful (Cellan Jones, James, Forsyte and Hindsight, Dudley: Kaleidoscope, 2006, p. 48).

${ }^{3}$ Sutton, 1982, p.103.

${ }^{4}$ Messina quoted in Drabble, Margaret, 'The Messina Touch', Radio Times, 13 December 1975, pp.179.

${ }^{5}$ Ibid.

${ }^{6}$ The BBC Archive only hold extracts from The Love-Girl and the Innocent and The Recruiting Officer.

${ }^{7}$ BBC WAC VR/75/701 (13 January 1976).

${ }^{8} \mathrm{BBC}$ WAC VR/74/307.

${ }^{9} \mathrm{BBC}$ WAC VR/71/388 (24 November 1971).

${ }^{10} \mathrm{BBC}$ WAC VR/74/307.

${ }^{11}$ BBC WAC VR/73/666 (13 December 1973).

${ }^{12}$ BBC WAC VR/75/701 (13 January 1976).

${ }^{13}$ Ibid.

${ }^{14}$ BBC WAC VR/74/307.

${ }^{15}$ BBC WAC VR/75/701 (13 January 1976).

${ }^{16}$ Hargreaves, Tracy, "'There's No Place Like Home": History and Tradition in The Forsyte Saga and the BBC, Journal of British Cinema and Television, 6/1, 2009, pp. 21- 40.

${ }^{17}$ Letter, Times, 6 March 1969.

${ }^{18} \mathrm{BBC}$ WAC VR/69/565.

${ }^{19}$ Dyer, Richard, Brief Encounter, London: BFI, 1993, pp. 43-4.

${ }^{20}$ BBC WAC VR/76/115 (23 March 1976).

${ }^{21}$ Ibid.
} 
${ }^{22}$ Ibid.

${ }^{23} \mathrm{BBC}$ WAC VR/75/307 (10 June 1975). 